\title{
CT imaging of one extended family cluster of corona virus disease 2019 (COVID-19) including adolescent patients and "silent infection"
}

\author{
Rui Xü ${ }^{1 \#}$, Mingshan $\mathrm{Du}^{2 \#}$, Linfeng $\mathrm{Li}^{3}$, Zhiming Zhen ${ }^{2}$, Huiyou Wang ${ }^{3}$, Xiaofei Hu${ }^{2}$ \\ ${ }^{1}$ Department of Radiology, Guizhou Provincial People's Hospital, Guiyang 550002, China; ${ }^{2}$ Department of Radiology, Southwest Hospital, Third \\ Military Medical University (Army Medical University), Chongqing 400038, China; ${ }^{3}$ Department of Radiology, Panzhou People's Hospital, Panzhou \\ 553500 , China
}

\#These authors contributed equally to this work.

Correspondence to: Huiyou Wang. Department of Radiology, Panzhou People’s Hospital, Panzhou 553500, China. Email: 757189450@qq.com; Xiaofei Hu. Department of Radiology, Southwest Hospital, Third Military Medical University (Army Medical University), Chongqing 400038, China. Email: harryzonetmmu@163.com.

Submitted Feb 17, 2020. Accepted for publication Feb 21, 2020.

doi: 10.21037/qims.2020.02.13

View this article at: http://dx.doi.org/10.21037/qims.2020.02.13

The emergence and spread of a novel coronavirus from Wuhan City, Hubei Province of China, has become a global health concern (1). On 30th January 2020, corona virus disease 2019 (COVID-19) was declared to be a global health emergency by the World Health Organization. Since the detection of the coronavirus in late December 2019, COVID-19 has spread beyond to all provinces in China and into 19 countries overseas $(2,3)$. We describe the CT images of one extended family cluster of COVID-19, with mainly asymptomatic patients or patients with only mild symptoms and negative CT findings.

\section{Case series description}

On Jan 27, 2020, we initially enrolled one patient who presented to Panzhou People's Hospital (Guizhou Province, China) with fever, sore throat symptoms. Five other members of this extended family also presented for the assessment of their health conditions. Eventually realtime fluorescence polymerase chain reaction of all the six patient's nasopharyngeal swab and sputum samples were positive for the 2019 novel coronavirus (SARS-CoV-2) nucleic acid.

Patient 1: a 40-year-old man presented to the hospital with a 7-day history of fever, 1-day history of sore throat for unknown cause. He indicated that he worked in Wuhan, China and had not been exposed to the seafood and live animal market in Wuhan, where has been identified as the centre of the outbreak. One of his colleagues had a confirmed diagnosis of COVID-19. He reported that he came to Panzhou on January 17 with his wife and son. At admission, his body temperature was $36.8^{\circ} \mathrm{C}\left(98.24^{\circ} \mathrm{F}\right)$ with rough breathing sounds of both lungs. Laboratory studies showed leukopenia (white blood cell count: $3.9 \times 10^{9} / \mathrm{L}$; normal range, $\left.4-10 \times 10^{9} / \mathrm{L}\right)$. There was elevated blood level for erythrocyte sedimentation rate $(43.58 \mathrm{~mm} / \mathrm{h}$; normal range, $<20 \mathrm{~mm} / \mathrm{h}$ ). Unenhanced chest CT showed multiple consolidative peripheral opacities with ground-glass opacities, and superimposed inter- and intralobular septal thickening in bilateral lungs (Figure $1 A, B, C, D$ ), consistent with imaging finding of COVID-19 (4-8). After receiving 3 days of treatment, combined with interferon inhalation and lopinavir/ritonavir, the patient reported symptoms were relieved, and repeat chest CT showed mild reduction in lesion size and decrease in extent of the consolidative peripheral opacities (Figure 1E,F,G,H).

Patient 2: a 38-year-old woman, wife of patient 1, presented to the hospital with a 5-day history of cough for unknown cause. She reported that she lived with her husband and son in Wuhan and had not been exposed to 


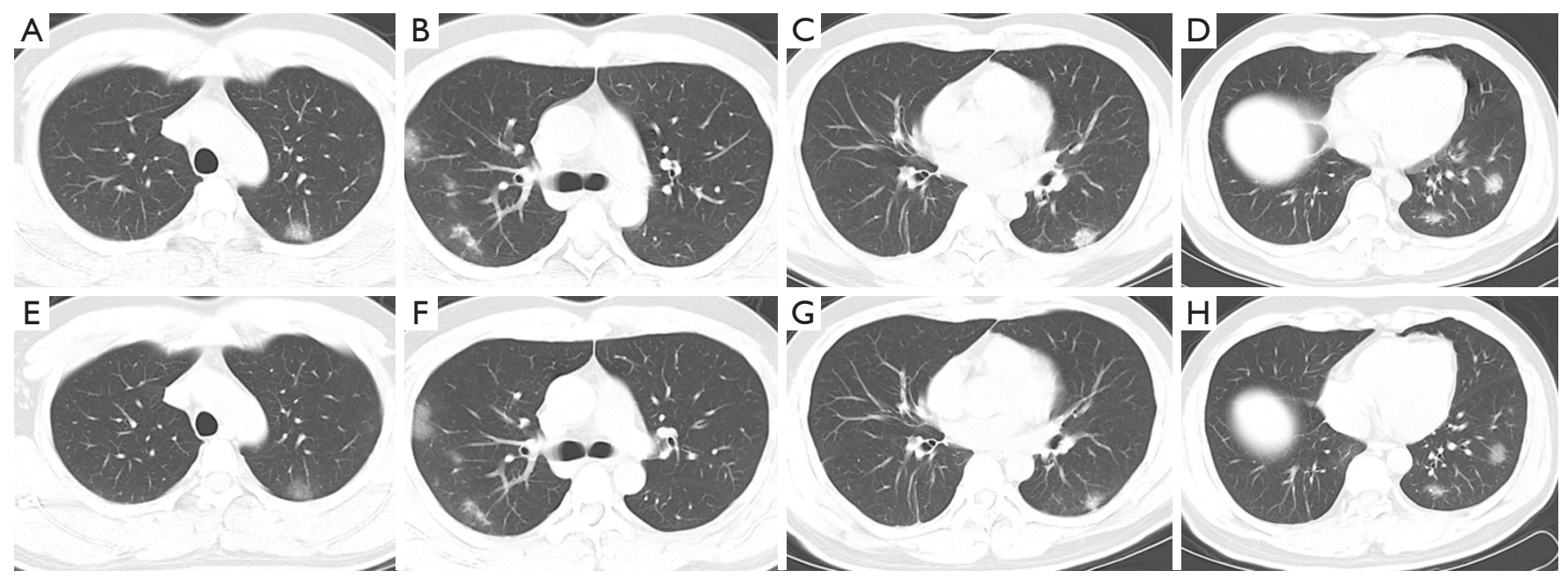

Figure 1 Unenhanced CT images of patient 1. (A,B,C,D) Images show the first CT. The bilateral lungs show multiple sub-solid nodules, patchy solid shadows with blurry boundaries and ground-glass opacities, with superimposed inter- and intralobular septal thickening, mainly distributed in a sub-pleural area. (B,D) Images obtained 3 days after A\&B, The density of some patchy solid shadows is reduced, showing "melting sugar" ground glass density.

the seafood and live animal market in Wuhan, and came to Panzhou on January 17. At admission, her body temperature was $36.5^{\circ} \mathrm{C}\left(97.7^{\circ} \mathrm{F}\right)$ with normal breathing sounds of both lungs. Laboratory studies showed leukopenia (white blood cell count: $3.9 \times 10^{9} / \mathrm{L}$; normal range, $4-10 \times 10^{9} / \mathrm{L}$ ) and lymphopenia (lymphocyte count: $0.6 \times 10^{9} / \mathrm{L}$ ). Unenhanced chest CT showed negative finding. After receiving 3 days of treatment, combined with interferon inhalation and lopinavir/ritonavir, the patient reported symptoms were relieved and repeat chest CT remained negative.

Patient 3: a 10-year-old asymptomatic boy, son of patient 1 and 2, presented for the assessment of his health condition. At admission, his body temperature was $36^{\circ} \mathrm{C}$ $\left(96.8^{\circ} \mathrm{F}\right)$ with normal breathing sounds of both lungs. Laboratory studies showed elevated blood levels for C-reactive protein $(5.38 \mathrm{mg} / \mathrm{L}$; normal range, $0-1 \mathrm{mg} / \mathrm{L})$. Unenhanced chest CT showed negative finding. After receiving 3 days of treatment, combined with interferon inhalation and lopinavir/ritonavir, repeat chest CT remained negative.

Patient 4: a 43-year-old man, the older brother of patient 1 , presented to the hospital with a 6-day history of chest tightness for unknown cause. He reported that he lived with his wife and daughter in Panzhou, and met patient 1 on January 17, the day patient 1 came Panzhou from Wuhan. He also reported that he had been a coal worker. At admission, his body temperature was $36.6^{\circ} \mathrm{C}\left(97.88^{\circ} \mathrm{F}\right)$ with rough breathing sounds of both lungs. Laboratory studies showed elevated blood levels for C-reactive protein (12.14 mg/L; normal range, $0-1 \mathrm{mg} / \mathrm{L})$. Unenhanced chest CT showed interstitial changes diffusely distributed in the bilateral lungs, and peripheral predominant solitary consolidative opacities with ground-glass opacities in right middle lobe (Figure $2 A, B$ ). The later is a common finding of COVID-19 (4-7). After receiving 3 days of treatment, combined with interferon inhalation and lopinavir/ ritonavir, the patient reported symptoms were relieved and repeat chest CT showed mild reduction in lesion size with decrease in extent of the ground-glass opacities and pleural thickening (Figure 2C,D).

Patient 5: a 41-year-old woman, wife of patient 4, presented to the hospital with a 3-day history of cough for unknown cause. She reported that she lived with her husband and daughter in Panzhou and had not travelled to Wuhan over the last year, and did not meet patient 1-3 these days. At admission, her body temperature was $37^{\circ} \mathrm{C}$ $\left(98.6^{\circ} \mathrm{F}\right)$ with normal breathing sounds of both lungs. Laboratory studies showed lymphopenia (lymphocyte count: $\left.0.68 \times 10^{9} / \mathrm{L}\right)$. Unenhanced chest CT showed negative findings (Figure $3 A, B$ ). After receiving 2 days of treatment, combined with interferon inhalation and lopinavir/ritonavir, the patient reported symptoms were relieved. However, repeat chest CT showed consolidative peripheral opacities with ground-glass opacities and the reversed halo sign in left lower lobe (Figure 3C,D).

Patient 6: a 18-year-old asymptomatic girl, daughter of 

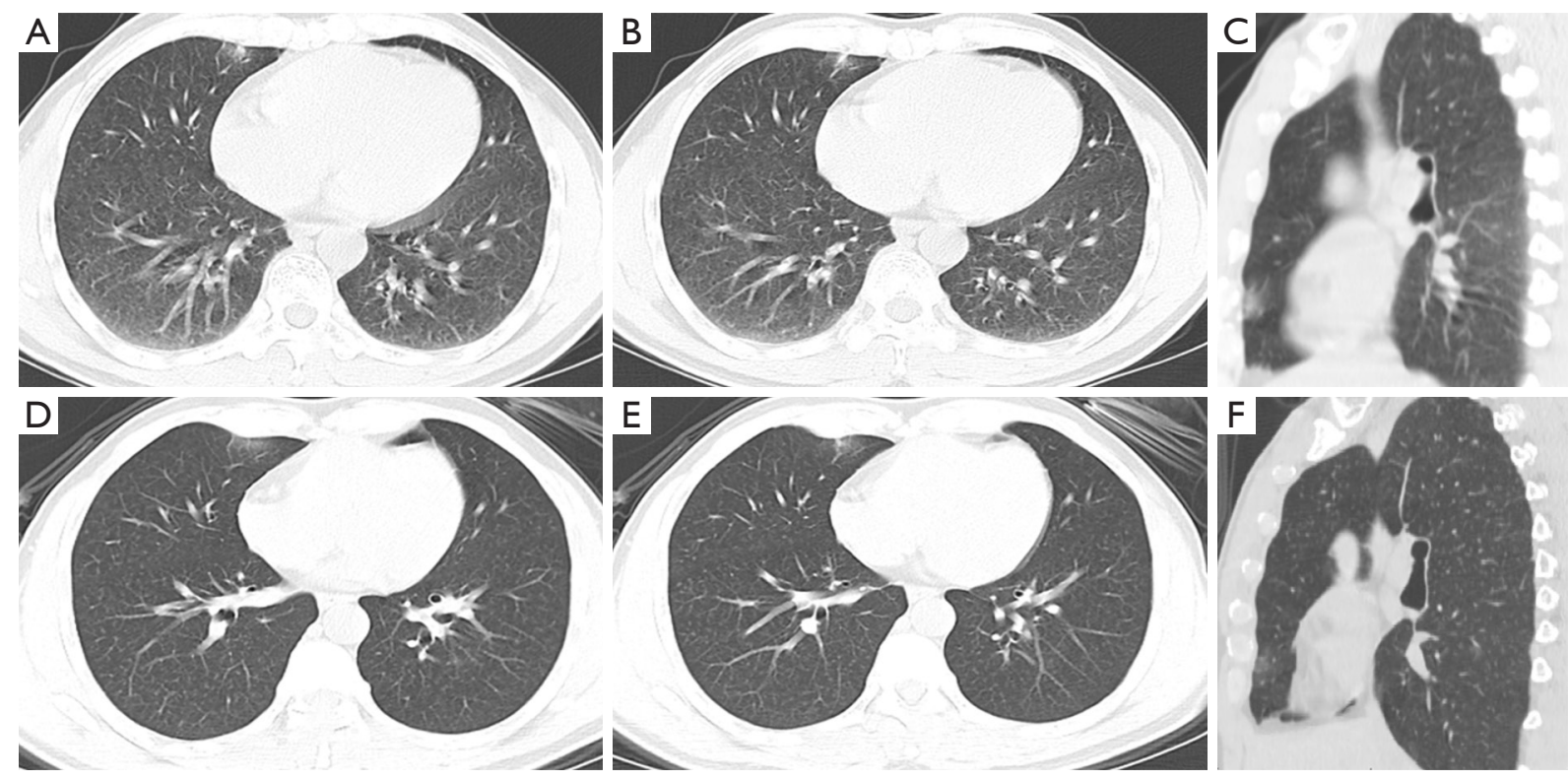

Figure 2 Unenhanced CT images of patient 4. (A,B,C) Images show interstitial changes diffusely distributed in the bilateral lungs, and a solitary, peripheral ground-glass, patchy solid shadows with blurry boundaries in right middle lobe, distributed in a sub-pleural area. (D,F) Images obtained 3 days after $(A, B, C)$ show mild reduction in lesion size with decrease in extent of the ground-glass opacities and pleural thickening.
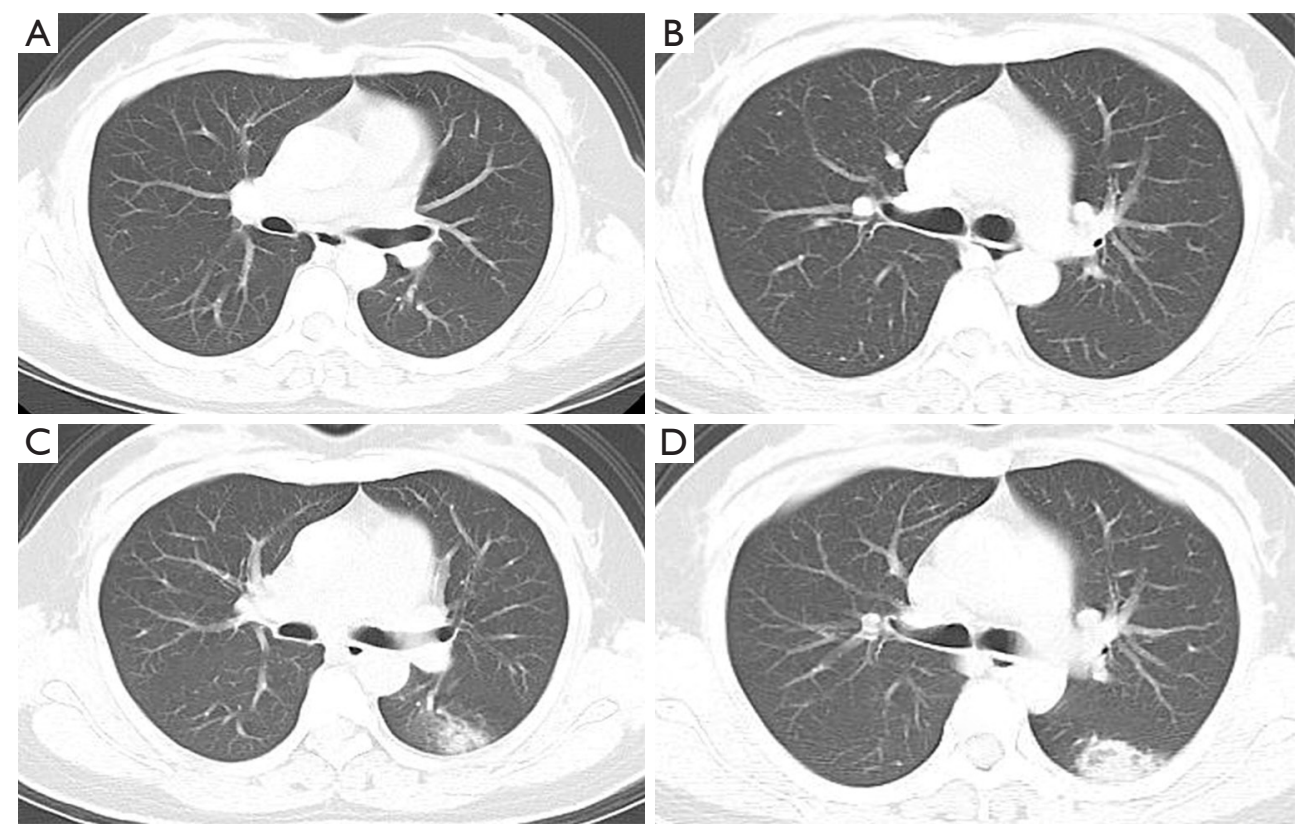

Figure 3 Unenhanced CT images of patient 5. (A,B) Image shows the first CT with negative findings. (C,D) Image obtained 3 days after $\mathrm{A} \& \mathrm{~B}$, shows consolidative pulmonary opacities with ground-glass opacities, and with sub-solid opacities centrally representing the reversed halo sign in left lower lobe. 
patient 4 and 5 , presented for the assessment of her health condition and had no history of contact with patient 1-3. At admission, her body temperature was $36^{\circ} \mathrm{C}\left(96.8^{\circ} \mathrm{F}\right)$ with normal breathing sounds of both lungs. Laboratory studies showed elevated blood levels for C-reactive protein (5.38 mg/L; normal range, $0-1 \mathrm{mg} / \mathrm{L})$. Unenhanced chest CT showed negative finding. After receiving 2 days of treatment, combined with interferon inhalation and lopinavir/ritonavir, repeat chest CT remained negative.

\section{Discussion}

Patient 1 was the index patient of the extended family, with the earliest symptoms and the most apparent imaging findings. According to Pan et al.'s study (8), Patient 1 had progressed to Stage-2, progressive stage, in which the infection extended to a bilateral multi-lobe distribution with sub-solid nodules, patchy solid shadows. These are common imaging findings of COVID-19 (4-8). The other patients were directly or indirectly infected from index patient with no or mild symptoms. The CT of other patients showed negative or mild abnormalities, and the mild CT changes were consistent with Stage-1, early stage (8).

Follow-up CT images showed negative or relieved findings, except patient 5 who showed progression, with inconsistency between clinical symptoms amelioration and imaging sign progression. Pathological study of COVID-19 implied that, although the mechanism by which the SARS$\mathrm{CoV}$-2 causes lung injury is poorly understood, the immune injury seems to play an important role (9). Some of the COVID-19 patients suddenly worsen after the onset of the disease, which may be related to overreaction of the immune system and excessive cytokine, leading to "cytokine storm" (10). The state of immune function and immune reaction in different individuals may be related to the different disease progression of the patients in the extended family.

When it comes the age factor, the patients of the family with apparent symptoms and CT findings were all adults, and the two adolescent patients had no symptoms and the CT were negative at onset and follow-up, consistent with the so-called "silent infection" (11). The same was observed in pediatric patients with severe acute respiratory syndrome (SARS), and the CT changes in children with SARS are more likely to be mild (12).

In order to better guide treatment and prognostic strategies, the program for the diagnosis and treatment of novel coronavirus (COVID-19) infected pneumonia (trial fifth edition) have been developed by National Health Commission of the People's Republic of China (13), and COVID-19 is divided into slight, common, severe and critical clinical types based on category of clinical symptoms, with different treatment options. Patient 2, 3, 5, 6 were of the slight type, with mild clinical symptoms and no imaging findings of pneumonia (13). Patients of COVID-19 with negative CT findings were also reported in other studies $(6,8)$. However, it was worth noting that patient with slight type had the ability to infect others already $(2,14)$. So special attention is required to these patients for the prevention and control of COVID-19. What's more, according to the program above, etiological detection is the gold standard method for the diagnosis of COVID-19, supported by epidemiological history and clinical manifestations including imaging features, clinical symptoms and CT (13). This study cohort demonstrates the high CT negative rate $(50 \%)$. Although the importance of CT in the diagnosis and evaluation of COVID-19 cannot be overstated, it should be avoided to rely entirely on CT for clinical diagnosis, especially in non-Wuhan and nonHubei area (15).

\section{Acknowledgments}

Funding: This work was supported by the National Nature Science Foundation of China (No. 81701664) and the Technology Innovation Program in Southwest Hospital (SWH2016JCYB-30).

\section{Footnote}

Conflicts of Interest: The authors have no conflicts of interest to declare.

Informed Consent: Written informed consent was obtained from the patient for publication of this study and any accompanying images.

Open Access Statement: This is an Open Access article distributed in accordance with the Creative Commons Attribution-NonCommercial-NoDerivs 4.0 International License (CC BY-NC-ND 4.0), which permits the noncommercial replication and distribution of the article with the strict proviso that no changes or edits are made and the original work is properly cited (including links to both the formal publication through the relevant DOI and the license). See: https://creativecommons.org/licenses/by-nc-nd/4.0/. 


\section{References}

1. Zhu N, Zhang D, Wang W, Li X, Yang B, Song J, Zhao X, Huang B, Shi W, Lu R, Niu P, Zhan F, Ma X, Wang D, Xu W, Wu G, Gao GF, Tan W. A Novel Coronavirus from Patients with Pneumonia in China, 2019. N Engl J Med 2020;382:727-33.

2. Huang C, Wang Y, Li X, Ren L, Zhao J, Hu Y, Zhang L, Fan G, Xu J, Gu X, Cheng Z, Yu T, Xia J, Wei Y, Wu W, Xie X, Yin W, Li H, Liu M, Xiao Y, Gao H, Guo L, Xie J, Wang G, Jiang R, Gao Z, Jin Q, Wang J, Cao B. Clinical features of patients infected with 2019 novel coronavirus in Wuhan, China. Lancet 2020;395:497-506.

3. Chan JF, Yuan S, Kok KH, To KK, Chu H, Yang J, Xing F, Liu J, Yip CC, Poon RW, Tsoi HW, Lo SK, Chan KH, Poon VK, Chan WM, Ip JD, Cai JP, Cheng VC, Chen H, Hui CK, Yuen KY. A familial cluster of pneumonia associated with the 2019 novel coronavirus indicating person-to-person transmission: a study of a family cluster. Lancet 2020;395:514-23.

4. Pan Y, Guan H, Zhou S, Wang Y, Li Q, Zhu T, Hu Q, Xia L. Initial CT findings and temporal changes in patients with the novel coronavirus pneumonia (2019-nCoV): a study of 63 patients in Wuhan, China. Eur Radiol 2020. doi: 10.1007/s00330-020-06731-x. [Epub ahead of print].

5. Lei J, Li J, Li X, Qi X. CT Imaging of the 2019 Novel Coronavirus (2019-nCoV) Pneumonia. Radiology 2020:. doi: 10.1148/radiol.2020200236. [Epub ahead of print].

6. Chung M, Bernheim A, Mei X, Zhang N, Huang M, Zeng X, Cui J, Xu W, Yang Y, Fayad ZA, Jacobi A, Li K, Li S, Shan H. CT Imaging Features of 2019 Novel Coronavirus (2019-nCoV). Radiology 2020. doi: 10.1148/ radiol.2020200230. [Epub ahead of print].

7. Liu P, Tan XZ. 2019 Novel Coronavirus (2019-nCoV) Pneumonia. Radiology 2020;295:19.

8. Pan F, Ye T, Sun P, Gui S, Liang B, Li L, Zheng D, Wang J, Hesketh RL, Yang L, Zheng C. Time Course of Lung Changes On Chest CT During Recovery From 2019 Novel Coronavirus (COVID-19) Pneumonia. Radiology 2020. doi: 10.1148/radiol.2020200370. [Epub ahead of print].

9. Xu Z, Shi L, Wang Y, Zhang J, Huang L, Zhang C, Liu S, Zhao P, Liu H, Zhu L, Tai Y, Bai C, Gao T, Song J, Xia P, Dong J, Zhao J, Wang FS. Pathological findings of COVID-19 associated with acute respiratory distress syndrome. Lancet Respir Med 2020. doi.org/10.1016/ S2213-2600(20)30076-X. [Epub ahead of print].

10. Srikiatkhachorn A, Mathew A, Rothman AL. Immunemediated cytokine storm and its role in severe dengue. Semin Immunopathol 2017;39:563-74.
11. Shen K, Yang Y, Wang T, Zhao D, Jiang Y, Jin R, Zheng Y, Xu B, Xie Z, Lin L, Shang Y, Lu X, Shu S, Bai Y, Deng J, Lu M, Ye L, Wang X, Wang Y, Gao L; China National Clinical Research Center for Respiratory Diseases; National Center for Children's Health, Beijing, China; Group of Respirology, Chinese Pediatric Society, Chinese Medical Association; Chinese Medical Doctor Association Committee on Respirology Pediatrics; China Medicine Education Association Committee on Pediatrics; Chinese Research Hospital Association Committee on Pediatrics; Chinese Non-government Medical Institutions Association Committee on Pediatrics; China Association of Traditional Chinese Medicine, Committee on Children's Health and Medicine Research; China News of Drug Information Association, Committee on Children's Safety Medication; Global Pediatric Pulmonology Alliance. Diagnosis, treatment, and prevention of 2019 novel coronavirus infection in children: experts' consensus statement. World J Pediatr 2020. doi: 10.1007/s12519-020-00343-7. [Epub ahead of print].

12. Chu WC, Li AM, Ng AW, So HK, Lam WW, Lo KL, Yeung MC, Yau YS, Chiu WK, Leung CW, Ng PC, Hon KL, Mo KW, Fok TF, Ahuja AT. Thin-Section CT 12 Months After the Diagnosis of Severe Acute Respiratory Syndrome in Pediatric Patients. AJR Am J Roentgenol 2006;186:1707-14.

13. General Office of National Health Committee. Office of State Administration of Traditional Chinese Medicine. Notice on the issuance of a programme for the diagnosis and treatment of novel coronavirus $(2019-\mathrm{nCoV})$ infected pneumonia (trial fifth edition). (2020-02-05) Available online: http://www.nhc.gov.cn/yzygj/s7653p/202002/3b09 b894ac9b4204a79db5b8912d4440.shtml

14. Phan LT, Nguyen TV, Luong QC, Nguyen TV, Nguyen HT, Le HQ, Nguyen TT, Cao TM, Pham QD. Importation and Human-to-Human Transmission of a Novel Coronavirus in Vietnam. N Engl J Med 2020. doi: 10.1056/NEJMc2001272. [Epub ahead of print].

15. Wáng YXJ, Liu WH, Yang $M$, Chen W. The role of CT for Covid-19 patient's management remains poorly defined. Ann Transl Med 2020;8:145.

Cite this article as: $\mathrm{Xu}$ R, Du M, Li L, Zhen Z, Wang H, Hu $\mathrm{X}$. CT imaging of one extended family cluster of corona virus disease 2019 (COVID-19) including adolescent patients and "silent infection". Quant Imaging Med Surg 2020;10(3):800804. doi: 10.21037/qims.2020.02.13 